\title{
Analysis of Brain Waves Before and After Plant Cutting Procedure
}

\author{
Sang Mi Lee', Gyung Mee Gim', Seon Hee Jeong', Sun Jin Jeong', Kyung Sook Han', Young Chea', \\ Yoonah Jang', Sook Lee ${ }^{2,3}$, and Hyun Jin Jang ${ }^{1,2}$ * \\ ${ }^{1}$ Agricultural Research Division, National Institute of Horticultural and Herbal Science, Rural Development Administration, Wanju \\ 55365, Korea \\ ${ }^{2}$ Department of Horticultural Therapy, Dankook University, Cheonan 16890, Korea \\ ${ }^{3}$ Department of Nursing, Dankook University, Cheonan 16890, Korea
}

\begin{abstract}
The purpose of this study was to analyze brain waves before and after the plant cutting procedure in 34 adult subjects. After plant cutting procedure, RT(Relative power of theta) decreased and RB(Relative power of beta), RMB(Relative power of mid beta), RHB(Relative power of high beta), RST(Ratio of SMR to theta spectrum), RMT(Ratio of mid beta to theta), and RSMT(Ratio of SMR mid beta to theta) increased, while RA(Relative power of alpha), RLB(Relative power of low beta), and RG (Relative power of gamma) did not change significantly. The decrease in the RT indicator means that the cutting did not cause anxiety as a stable work rather than a high level task. Therefore, it is considered that the cutting activity can be applied to the subjects with low cognitive level such as children, dementia, and intellectual disabilities and those who should avoid the psychological burden due to the performance of the work. The increases in RB, RMB, and RHB indicators mean a state of mental awakening, inducing concentration similar to meditation. Therefore, the activity of cutting can be applied to people who use psychological energy in daily life, psychological confusion, excessive unnecessary thought, troublesome problems. The increases in the RST, RMT, and RSMT indicators mean an increase in concentration. Therefore, it is possible to apply the cutting activity for the purpose of strengthening the attention and intensifying induction. The results of this study are meaningful that it was confirmed that the cutting activity could induce the brain to be awakened by inducing concentration through conscious activities without giving an intellectual anxiety or psychological burden.
\end{abstract}

Keywords: $\alpha$ wave, activation of EEG, horticultural activity, plant cutting

\section{Introduction}

According to the overload and arousal theory of Ulrich and Parsons (1992), surrounding environments in the modern society such as noise, movement and visual complexity constantly overwhelm human senses, and cause psychological and physiological excitement. Meanwhile, environments surrounded by plants are less complex, have patterns that reduce arousal, and thus reduce stress (Simson and Straus, 1998). For this reason, plants have been often used as a medium for healing recently.

'Horticultural therapy' is one of the most popularly used services utilizing plants. Horticultural therapy was searched as

This study was supported by grants from the Rural Development Administration (PJ011376012017).

Received: September 1, 2018, Revised: October 3, 2018, Accepted: October 15, 2018

First author: Sang Mi Lee, E-mail: sangmilee@korea.kr, ORCID: 0000-0003-1049-4705

*Corresponding author: Hyun Jin Jang, E-mail:jin23002300@naver.com, ORCID: 0000-0003-3505-217X

2018 by the Society for People, Plants, and Environment. This is an Open Access article distributed under the terms of the Creative Common Attribution Non-Commercial License (http://creativecommons.org/licenses/by-nc/4.0/) which permits unrestricted non-commercial use, distribution, and reproduction in any medium, provided the original work is properly cited. 
a keyword in the Research Information Service System (RISS), and it was found that a total of 281 studies were registered in South Korea for the past 5 years (2014 2018). They include 231 experimental studies, 32 research studies and 18 other studies such as those on developing programs. Out of the 231 experimental studies, 221 studies used questionnaires, and the rest 10 studies used physiological indicators such as blood test, pinch test and three-dimensional motion analysis. Studies on the effects of horticultural therapy programs have been actively conducted, but there are little studies using physiological indicators. The physiological indicators used in earlier studies include cortisol and serotonin using a blood test (Lee et al., 2017a), the muscular strength of the fingers using a pinch test (Kim, 2015), blood pressure, pulse (Yun, 2007), etc. These studies are still about the effects of horticultural therapy programs that provide a series of sessions of horticultural activities. In order to identify the effects of horticultural activities on humans, it is necessary to analyze the effects of individual activities that compose a program, and these analysis results can be actively utilized to select horticultural activities suitable for subjects in performing horticultural therapy (Lee et al., 2017b).

Against this backdrop, this study aimed to analyze the brain waves of subjects before and after participating in activities of cutting plants as a follow-up study of Lee et al. (2017b) on the analysis of changes in brain waves before and after sowing seeds, to identify the effects of activities of cutting plants, and to support the selection of target subjects.

\section{Methods}

\section{Subjects}

This study was conducted among 36 right-handed adults in their 20 s to 60 s who had an experience of participating in horticultural activities, and the data of a total of 34 adults ( 27 females and 7 males), except those whose data have errors were analyzed. They were recruited through an announcement of the National Institute of Horticultural and Herbal Science. Those who voluntarily consented to participate in this study were informed of the purpose and process of this study, and signed a consent form, which was copied. One was given to the subject and the other was kept by the researcher of this study. The average age of the subjects was $41.32 \pm 14.59$ years, and their average height and weight were $163.47 \pm 8.11 \mathrm{~cm}$ and $62.85 \pm 12.91 \mathrm{~kg}$ respectively.

\section{Laboratory Preparation}

This experiment was carried out in a windowless laboratory (length: $320 \mathrm{~cm}$, width: $250 \mathrm{~cm}$, height: $265 \mathrm{~cm}$ ) located in the National Institute of Horticultural and Herbal Science (Lee et al., 2017b). A white table (length: 100cm, width: $50 \mathrm{~cm}$, height: $60 \mathrm{~cm}$ ) and a high-backed chair were placed in the laboratory. An analysis sheet on the process of cutting plants was attached on the wall $150 \mathrm{~cm}$ in front of the subject for him or her to refer to. The average temperature, humidity, noise and illuminance of the laboratory was $24.86 \pm 0.70^{\circ} \mathrm{C}, 48.62 \pm 12.85 \%, 48.59 \pm 1.82 \mathrm{db}$, and $33.956 \pm 20.991 \mathrm{ux}$ respectively.

\section{Worktable Preparation}

A stainless ball (diameter: $26 \mathrm{~cm}$, height: $10 \mathrm{~cm}$, weight: $255 \mathrm{~g}$ ) was placed in the lower right area of the center of the worktable, and a pair of scissors (length: $20 \mathrm{~cm}$, weight: $65 \mathrm{~g}$ ) was placed on the right side of the stainless ball. A watering can that contained $60 \mathrm{ml}$ of water (diameter: $11 \mathrm{~cm}$, height: $13 \mathrm{~cm}$, total weight: $261 \mathrm{~g}$ ) was placed right above the scissors, and a zipper bag that contained $300 \mathrm{ml}$ of bed soil used for horticultural purposes (width: $16 \mathrm{~cm}$, length: $17 \mathrm{~cm}$, total weight: $70 \mathrm{~g}$ ) was placed on the left side of the watering can. A beaker that contained $40 \mathrm{ml}$ of water (diameter: $6.5 \mathrm{~cm}$, height: $7 \mathrm{~cm}$, total weight: 56g) was placed on the left side of the zipper bag, and a black-colored plastic trowel (length: 26cm, width: 
$7 \mathrm{~cm}$, weight: $52 \mathrm{~g}$ ) was placed on the left side of the beaker. A 3-hole empty plug tray (width: $15.5 \mathrm{~cm}$, length: $5 \mathrm{~cm}$, height: $5 \mathrm{~cm}$, weight: $7 \mathrm{~g}$ ) was placed on the left side of the trowel, and a pot of Chrysanthemum (total height: $20-25 \mathrm{~cm}$ ) was placed on the left side of the tray. A white label (width: $4.5 \mathrm{~cm}$, length: $7 \mathrm{~cm}$, weight: $1 \mathrm{~g}$ ) was placed on the left side of the pot, and a black name pen (length: $13.5 \mathrm{~cm}$, weight: $8 \mathrm{~g}$ ) was placed on the left side of the white label (Figure 1).

\section{Subject Preparation}

The characteristics of normal brain waves differ depending on the conditions of the body such as sleeping, arousal and sleepiness (Korean Society of EEG Research, 2017). For this reason, Kim et al. (2017) suggests the following guidelines for obtaining quality EEG data. Subjects are instructed not to drink alcohol but to get enough sleep on the day prior to measuring EEG. They are ensured to refrain from consuming caffeine and nicotine, and they are also instructed to wash their hair but not to apply hair care products over the hair on the day prior to the experiment.

In this study, the subjects were instructed to get enough sleep and not to drink alcohol on the day prior to this experiment, and not to drink coffee or stimulants (energy drinks) for one hour prior to this experiment. They were also instructed not to excessively exercise before participating in this experiment. In addition, the subjects were instructed, if possible, to wash and dry their hair before coming to the laboratory in order to collect electrical signals transmitted from the scalp more efficiently. They were also instructed to fully understand the process of cutting plants. After arriving at the laboratory on the day of the experiment, they took a rest for over 10 minutes. The researcher of this study informed the subjects of the purpose and process of this study, and the subjects read the overview of this experiment and read and signed the consent form for this experiment. After that, they changed into a laboratory gown in a changing room, and electrodes were attached on the head of the subjects in the laboratory.

\section{Attachment of Electrodes and Measurement of Brain Waves}

To analyze the brain waves of the subjects, electroencephalogram (EEG) in which electrical changes in the brain are measured by putting a cap attached with electrodes on the head was adopted. Brain waves are changes in an electrical current caused by the flow of ions within neurons in the brain, and electroencephalogram (EEG) is defined as the flow of the

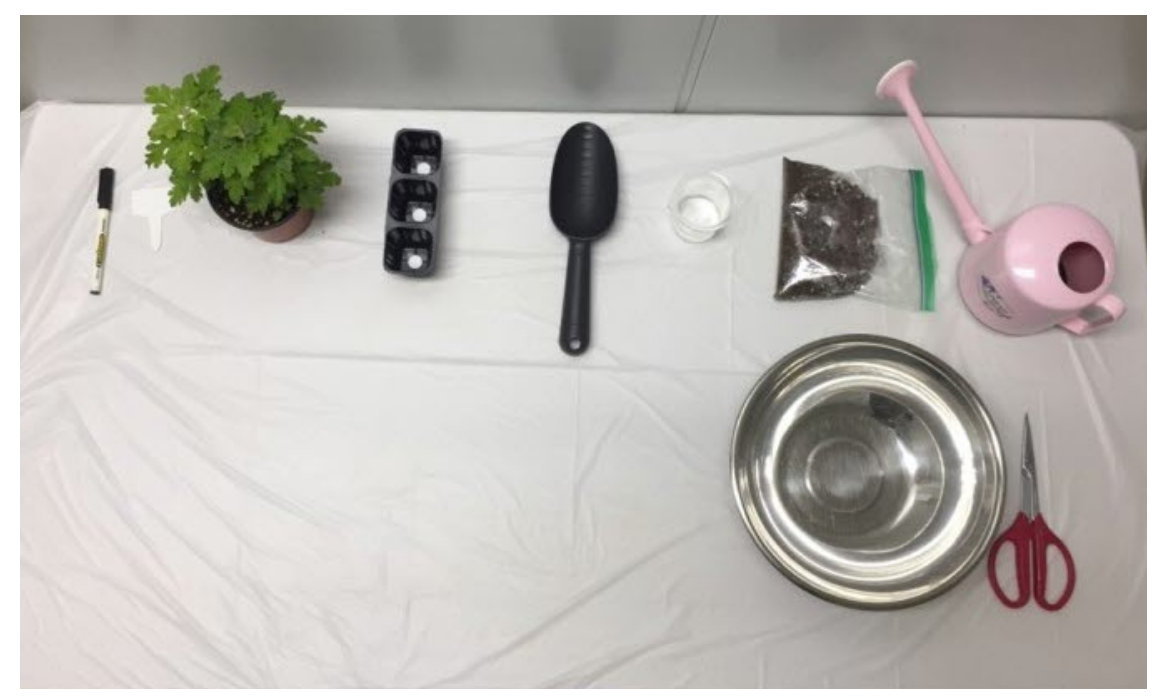

Figure 1. Table setting for plant cutting procedure. 
electrical current and an act of measuring the flow (Niedermeyer and Lopes da Silva, 2005). EEG signals were measured using BIOS24 (Biobrain inc., Daejeon, Korea), a 24-channel wired polygraph system. The measured analog signals were sampled at $250 \mathrm{~Hz}$ into digital signals, and were sent via USB to a personal computer. The transmitted digital EEG signals were filtered using an EEG analysis program called BioScan (Biobrain inc., Daejeon, Korea). EEG rhythms were analyzed by frequency range, and spectrum values were calculated by reflecting the quantitative amount of EEG rhythms.

In this experiment, Relative power of theta(RT), Relative power of alpha(RA), Relative power of beta(RB), Relative power of low beta(RLB), Relative power of mid beta(RMB), Relative power of high beta(RHB), Relative power of gamma(RG), Ratio of SMR to theta(RST), Ratio of mid beta to theta(RMT) and Ratio of SMR mid beta to theta(RSMT) were analyzed.

RT (relative power of theta) is the relative power spectrum value obtained by dividing the theta wave (4-8 $\mathrm{Hz}$ ) by the entire frequency range $(4-50 \mathrm{~Hz})$, and is known to increase more when thinking creatively and scientifically or solving problems in an intelligent test than in a stable state (Kim and Chang, 2001; Kwon, at al., 2006). RA (relative power of alpha) is the relative power spectrum value obtained by dividing the alpha wave $(8-13 \mathrm{~Hz})$ by the entire frequency range $(4-50 \mathrm{~Hz})$, and is known to increase when the brain function is relaxed and stable, and to decrease when solving complicated and difficult tasks (Yeon, 2013). RB (relative power of beta) is the relative power spectrum value obtained by dividing the beta wave $(13-30 \mathrm{~Hz})$ by the entire frequency range $(4-50 \mathrm{~Hz})$, and is known to increase more mainly in the parietal lobe in a state of arousal or when doing conscious acts than in a stable state (Yeon, 2013). RLB (relative power of low beta) is the relative power spectrum value obtained by dividing the low beta wave $(12-15 \mathrm{~Hz})$ by the entire frequency range $(4-50 \mathrm{~Hz})$, and is known to increase in the process of cognition or when highly concentrating on something (Jo, 2014). RMB (relative power of mid beta) is the relative power spectrum value obtained by dividing the mid beta wave $(15-20 \mathrm{~Hz})$ by the entire frequency range $(4-50 \mathrm{~Hz})$, and is known to increase when feeling sleepy or meditating. It is also known that the higher the value, the higher the concentration level (Lee, 2011). RHB (relative power of high beta) is the relative power spectrum value obtained by dividing the high beta wave $(20-30 \mathrm{~Hz})$ by the entire frequency range (4-50 $\mathrm{Hz}$ ), and is known to increase under severe stress or in an excited state (Jo, 2014). RG (relative power of gamma) is the relative power spectrum value obtained by dividing the gamma wave $(30-50 \mathrm{~Hz})$ by the entire frequency range $(4-50 \mathrm{~Hz})$, and is known to increase under visual stimulation or in an emotionally nervous state, or when doing cognitive activities such as inference and judgement (Yeon, 2013; Jo, 2014). RST (ratio of SMR to theta spectrum) is the spectrum value obtained by dividing the SMR (Sensorimotor rhythm) wave (12-15 Hz) by the theta wave (4-8Hz), and is known to occur when attention reaches its peak (T.H. Kim, 2018). RMT (ratio of mid beta to theta) is the ratio of the mid beta wave to the theta wave in the entire frequency range, and is known to involve in attention and concentration. The higher the RMT value, the higher the concentration level (Lee, 2011; Yeon, 2013). RSMT (ratio of SMR mid beta to theta) is the spectrum value obtained by dividing the SMR mid beta wave range $(12-20 \mathrm{~Hz})$ by the theta wave $(4-8 \mathrm{~Hz})$, and the higher the RSMT value, the higher the concentration level (Jo, 2014; Lee, 2011; Yeon, 2013).

To measure the reference value for a EEG electrode cap and EEG signals before measuring EEG, the reference electrode was attached on the earlobe like a clip, and according to the International 10-20 system, a total of 21 electrodes were placed (Figure 2). In this experiment, two electrodes (Fpz and $\mathrm{Oz}$ ) in the area where electrodes are concentrated were excluded, and the data of a total of 19 electrodes were collected. The data of C3, CZ and C4 located in the middle part of the brain were also collected, but they were excluded as they are located in the boundary area between the frontal lobe and the parietal lobe.

The EEG of the subjects was measured in a relaxed state in a seated position with the eyes closed for one minute before starting the activity of cutting and for one minute after finishing the activity (Figure 3). 


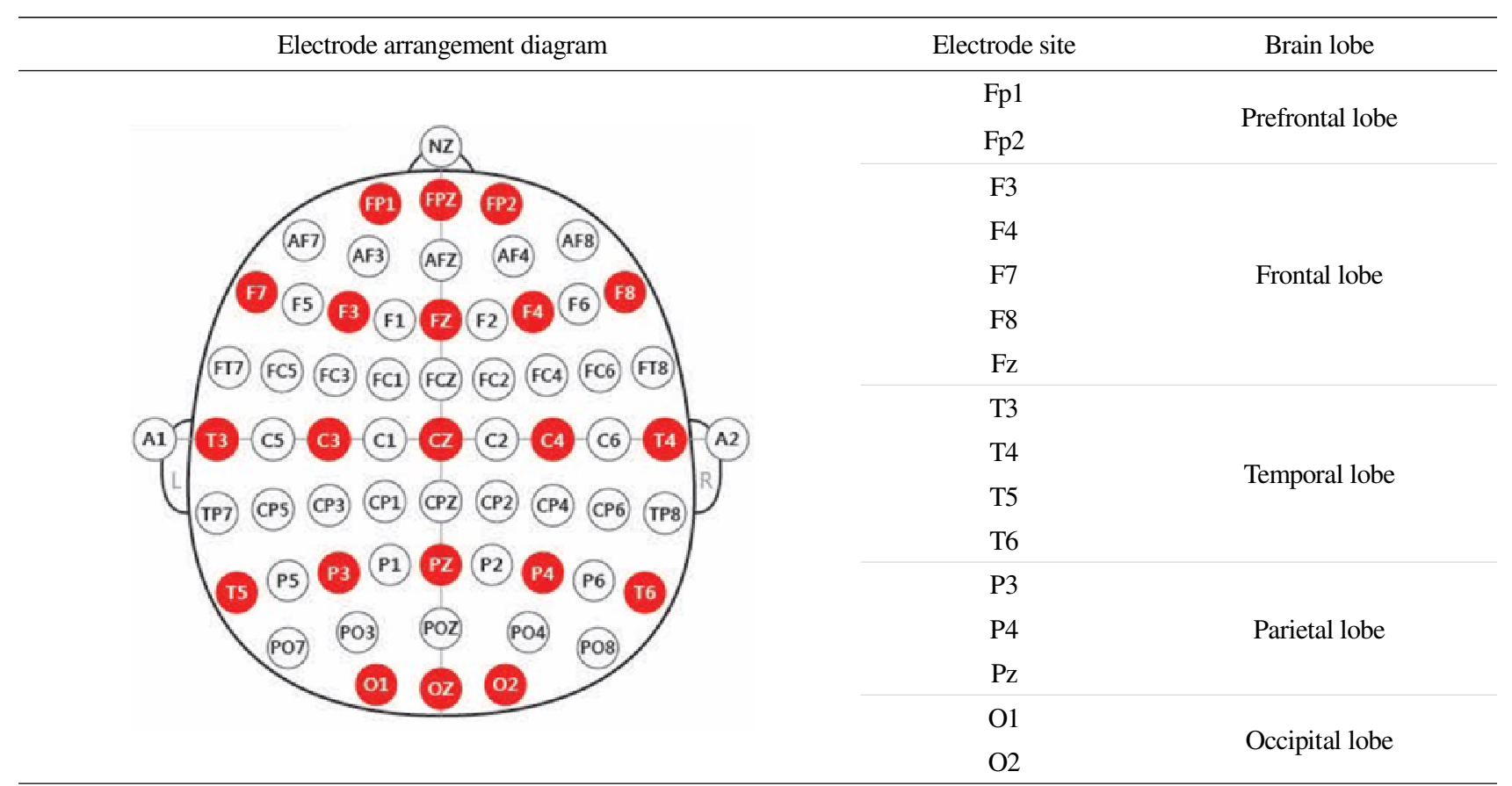

Figure 2. Electrode cap arrangement diagram and brain lobe.

Electrode cap

Figure 3. Electrode equipment and position for EEG measurement.

\section{Composition of Activities of Cutting Plants}

The process of cutting plants was composed of a total of 5 stages including mixing soil; filling soil; cutting plants; writing labels; and watering (Table 1). According to the instructions given by the researcher, the subjects performed the activities by referring to the analysis sheet on the entire process attached on the wall in front of them. This experiment had been performed from August to November, 2017.

\section{Data Processing and Statistical Analysis Methods}

To analyze EEG data, the data were processed using the following statistical analysis methods. The average value and 
Table 1. Plant cutting process

\begin{tabular}{|c|c|c|c|}
\hline & Step & Contents & \\
\hline \multirow{7}{*}{ 1. Mixing soil } & 1 & Bring the stainless bowl to the center of your body & \\
\hline & 2 & Break up and loose hard soil with scissors & \\
\hline & 3 & Pour all the soil into the stainless bowl & \\
\hline & 4 & Pour all the water in a plastic beaker into the stainless bowl & \\
\hline & 5 & Mix water and soil evenly by hand & \\
\hline & 6 & Dust off your hands & \\
\hline & 7 & Push the stainless bowl slightly to the right & \\
\hline \multirow{5}{*}{ 2. Filling soil } & 8 & Bring the plastic pot tray to the center of the body & \\
\hline & 9 & Hold a garden shovel with your right hand & \\
\hline & 10 & Fill the tray with soil using a garden shovel & \\
\hline & 11 & Flatten the top of the plastic pot tray. & \\
\hline & 12 & Dust off your hands & \\
\hline \multirow{7}{*}{ 3. Cutting } & 13 & Bring the flower pot (chrysanthemum) to the center of the body & \multirow{7}{*}{ Repeat 3 times } \\
\hline & 14 & Hold your scissors with your right hand & \\
\hline & 15 & From the plant (chrysanthemum), take a stem of a plant with your left hand & \\
\hline & 16 & Cut the 5th to 6th sections from the top of the selected stem with scissors & \\
\hline & 17 & Put down the scissors & \\
\hline & 18 & Remove the two leaves from the bottom of the cutting with your right hand & \\
\hline & 19 & $\begin{array}{l}\text { Move the stem (chrysanthemum) with your right hand and insert it deep into the } \\
\text { center of one cell of the tray }\end{array}$ & \\
\hline \multirow{2}{*}{ 4. Writing labels } & 30 & Write the name of the plant (chrysanthemum) and date on the label & \\
\hline & 31 & Place the label on the front edge of the tray & \\
\hline \multirow{3}{*}{ 5. Watering } & 32 & Hold the pot tray with your right hand & \\
\hline & 33 & Gives all the water to the tray & \\
\hline & 34 & Put down the tray & \\
\hline 6. Wrap-up & 35 & Rest your hand on the table & \\
\hline
\end{tabular}

standard deviation of the brain wave indicators (RT, RST, RMT, RSMT) before and after performing the activities by the area of the brain (prefrontal lobe, frontal lobe, temporal lobe, occipital lobe) were analyzed using descriptive statistics. Differences in EEG between before and after performing the activities by the area of the brain were statistically tested using SPSS Win Ver. 22.0, a statistical analysis program. The number of subjects whose data were analyzed in this study was 34 . When a group composed of 30 subjects or more is in general recognized as a normally distributed group (Bae, 2012), and thus a paired T test was performed. The significance level was .05.

\section{Results and Discussion}

The average time consumed for performing the activities of cutting plants was $268 \pm 66$ seconds.

\section{Changes in RT Before and After Performing the Activities}

RT before and after performing the activities of cutting plants was analyzed, and RT in F4 ( $p=.034)$ and O1 ( $p=.033)$ 
Table 2. Changes in Relative power of theta (RT) waves before and after plant cutting work

\begin{tabular}{|c|c|c|c|c|c|}
\hline \multirow{2}{*}{ Brain lobe } & \multirow{2}{*}{ Site } & \multicolumn{2}{|c|}{$\mathrm{M} \pm \mathrm{SD}(\mu \mathrm{V} 2)$} & \multirow{2}{*}{$\mathrm{t}$} & \multirow{2}{*}{$p$} \\
\hline & & Before & After & & \\
\hline \multirow{2}{*}{ Prefrontal lobe } & $\mathrm{Fp} 1^{\mathrm{z}}$ & $0.404 \pm 0.147$ & $0.384 \pm 0.163$ & 0.757 & .454 \\
\hline & Fp2 & $0.404 \pm 0.143$ & $0.378 \pm 0.160$ & 1.166 & .252 \\
\hline \multirow{5}{*}{ Frontal lobe } & $\mathrm{F} 3$ & $0.379 \pm 0.152$ & $0.359 \pm 0.174$ & 0.872 & .389 \\
\hline & $\mathrm{F} 4$ & $0.404 \pm 0.145$ & $0.368 \pm 0.164$ & 2.215 & $.034^{*}$ \\
\hline & F7 & $0.421 \pm 0.126$ & $0.405 \pm 0.141$ & 0.841 & .406 \\
\hline & F8 & $0.412 \pm 0.130$ & $0.393 \pm 0.159$ & 0.846 & .403 \\
\hline & $\mathrm{Fz}$ & $0.406 \pm 0.142$ & $0.372 \pm 0.168$ & 1.893 & .067 \\
\hline \multirow{4}{*}{ Temporal lobe } & $\mathrm{T} 3$ & $0.380 \pm 0.151$ & $0.359 \pm 0.177$ & 0.872 & .389 \\
\hline & $\mathrm{T} 4$ & $0.394 \pm 0.148$ & $0.362 \pm 0.174$ & 1.289 & .206 \\
\hline & T5 & $0.361 \pm 0.162$ & $0.329 \pm 0.184$ & 1.507 & .141 \\
\hline & T6 & $0.365 \pm 0.156$ & $0.350 \pm 0.186$ & 0.639 & .527 \\
\hline \multirow{3}{*}{ Parietal lobe } & P3 & $0.374 \pm 0.157$ & $0.349 \pm 0.173$ & 0.967 & .340 \\
\hline & $\mathrm{P} 4$ & $0.353 \pm 0.157$ & $0.335 \pm 0.185$ & 0.814 & .422 \\
\hline & $\mathrm{Pz}$ & $0.352 \pm 0.164$ & $0.318 \pm 0.184$ & 1.302 & .202 \\
\hline \multirow{2}{*}{ Occipital lobe } & O1 & $0.371 \pm 0.148$ & $0.319 \pm 0.185$ & 2.227 & $.033^{*}$ \\
\hline & $\mathrm{O} 2$ & $0.376 \pm 0.153$ & $0.347 \pm 0.186$ & 1.239 & .224 \\
\hline
\end{tabular}

${ }^{\mathrm{z}}$ See Figure 2 for the detailed position.

*Significant at $p<.05$ level by paired t-test.

statistically significantly decreased after performing the activities compared to the value before performing the activities. RT in the rest areas also tended to decrease, but there was no statistically significant difference (Table 2).

RT (relative power of theta) tends to increase more when thinking creatively and scientifically or solving problems in an intelligent test than in a stable state, and tends to increase, in particular, when the level of tasks to be solved is high (Kim and Chang, 2001; Kwon et al., 2006). In the case of adults, RT increases in an emotionally nervous state caused by frustrated experiences and consequent disappointment (T.H. Kim, 2018). In addition, the theta wave increases when the eyes are closed, and this is commonly observed in a state of sleepiness, which is the first stage of sleep (Vaitl et al., 2005; Park and Sung, 2006; Gruzelier, 2009). The theta wave is also known to be functionally related to the encoding and retrieval of information in the work memory (Vernon et al., 2003). RT decreased in this study not because the activities of cutting plants are high-level tasks that require the encoding and retrieval of information and solving problems, but because they are the tasks that can be stably performed, and thus did not cause anxiety in this study. In addition, the theta wave decreases when the eyes are closed, which means that they are in a stable but awake state, not in a sleepy state. Utilizing these results, the activities of cutting plants can be applied to those who have low cognitive ability such as children, the elderly with dementia, and people with intellectual disability or those who need to reduce psychological burdens.

\section{Changes in RA Before and After Performing the Activities}

RA before and after performing the activities was analyzed, but there was no statistically significant difference (Table 3 ).

\section{Changes in RB, RLB, RMB and RHB Before and After Performing the Activities}

$\mathrm{RB}$ before and after performing the activities was analyzed, and RB in F4 ( $p=.009)$ and $\mathrm{O} 1$ ( $p=.030)$ statistically significantly increased after performing the activities compared to the value before performing the activities (Table 4). 
Table 3. Changes in Relative power of alpha (RA) waves before and after plant cutting work

\begin{tabular}{|c|c|c|c|c|c|}
\hline \multirow{2}{*}{ Brain lobe } & \multirow{2}{*}{ Site } & \multicolumn{2}{|c|}{$\mathrm{M} \pm \mathrm{SD}(\mu \mathrm{V} 2)$} & \multirow{2}{*}{$\mathrm{t}$} & \multirow{2}{*}{$p$} \\
\hline & & Before & After & & \\
\hline \multirow{2}{*}{ Prefrontal lobe } & $\mathrm{Fp} 1^{\mathrm{z}}$ & $0.196 \pm 0.061$ & $0.187 \pm 0.043$ & 1.134 & .265 \\
\hline & $\mathrm{Fp} 2$ & $0.195 \pm 0.050$ & $0.197 \pm 0.063$ & -0.177 & .861 \\
\hline \multirow{5}{*}{ Frontal lobe } & F3 & $0.191 \pm 0.050$ & $0.191 \pm 0.063$ & -0.027 & .979 \\
\hline & $\mathrm{F} 4$ & $0.199 \pm 0.050$ & $0.198 \pm 0.065$ & 0.093 & .927 \\
\hline & F7 & $0.198 \pm 0.045$ & $0.192 \pm 0.039$ & 1.147 & .259 \\
\hline & F8 & $0.192 \pm 0.034$ & $0.196 \pm 0.053$ & -0.555 & .583 \\
\hline & $\mathrm{Fz}$ & $0.202 \pm 0.061$ & $0.208 \pm 0.074$ & -0.620 & .540 \\
\hline \multirow{4}{*}{ Temporal lobe } & $\mathrm{T} 3$ & $0.195 \pm 0.029$ & $0.195 \pm 0.036$ & 0.037 & .971 \\
\hline & $\mathrm{T} 4$ & $0.199 \pm 0.038$ & $0.194 \pm 0.046$ & 0.839 & .407 \\
\hline & T5 & $0.251 \pm 0.076$ & $0.258 \pm 0.097$ & -0.589 & .560 \\
\hline & T6 & $0.269 \pm 0.104$ & $0.276 \pm 0.125$ & -0.598 & .554 \\
\hline \multirow{3}{*}{ Parietal lobe } & P3 & $0.267 \pm 0.104$ & $0.274 \pm 0.118$ & -0.463 & .646 \\
\hline & $\mathrm{P} 4$ & $0.287 \pm 0.125$ & $0.291 \pm 0.127$ & -0.314 & .756 \\
\hline & $\mathrm{Pz}$ & $0.255 \pm 0.098$ & $0.253 \pm 0.139$ & 0.139 & .891 \\
\hline \multirow{2}{*}{ Occipital lobe } & $\mathrm{O} 1$ & $0.271 \pm 0.083$ & $0.281 \pm 0.116$ & -0.828 & .413 \\
\hline & $\mathrm{O} 2$ & $0.259 \pm 0.106$ & $0.273 \pm 0.122$ & -1.096 & .281 \\
\hline
\end{tabular}

${ }^{\mathrm{z}}$ See Figure 2 for the detailed position.

*Significant at $p<.05$ level by paired t-test.

Table 4. Changes in Relative power of beta (RB) waves before and after plant cutting work

\begin{tabular}{|c|c|c|c|c|c|}
\hline \multirow{2}{*}{ Brain lobe } & \multirow{2}{*}{ Site } & \multicolumn{2}{|c|}{$\mathrm{M} \pm \mathrm{SD}(\mu \mathrm{V} 2)$} & \multirow{2}{*}{$\mathrm{t}$} & \multirow{2}{*}{$p$} \\
\hline & & Before & After & & \\
\hline \multirow{2}{*}{ Prefrontal lobe } & $\mathrm{Fp}^{\mathrm{z}}$ & $0.222 \pm 0.054$ & $0.231 \pm 0.051$ & -0.979 & .335 \\
\hline & Fp2 & $0.224 \pm 0.056$ & $0.230 \pm 0.051$ & -0.659 & .514 \\
\hline \multirow{5}{*}{ Frontal lobe } & $\mathrm{F} 3$ & $0.227 \pm 0.051$ & $0.232 \pm 0.049$ & -0.639 & .527 \\
\hline & $\mathrm{F} 4$ & $0.219 \pm 0.048$ & $0.235 \pm 0.050$ & -2.751 & $.009^{*}$ \\
\hline & F7 & $0.220 \pm 0.045$ & $0.231 \pm 0.052$ & -1.356 & .184 \\
\hline & F8 & $0.227 \pm 0.054$ & $0.234 \pm 0.058$ & -0.844 & .404 \\
\hline & $\mathrm{Fz}$ & $0.217 \pm 0.050$ & $0.227 \pm 0.044$ & -1.691 & .100 \\
\hline \multirow{4}{*}{ Temporal lobe } & $\mathrm{T} 3$ & $0.236 \pm 0.062$ & $0.246 \pm 0.063$ & -1.289 & .206 \\
\hline & $\mathrm{T} 4$ & $0.228 \pm 0.055$ & $0.245 \pm 0.061$ & -1.973 & .057 \\
\hline & T5 & $0.220 \pm 0.058$ & $0.232 \pm 0.068$ & -1.959 & .058 \\
\hline & T6 & $0.212 \pm 0.050$ & $0.222 \pm .054$ & -1.461 & .153 \\
\hline \multirow{3}{*}{ Parietal lobe } & $\mathrm{P} 3$ & $0.214 \pm 0.054$ & $0.223 \pm 0.056$ & -1.353 & .185 \\
\hline & $\mathrm{P} 4$ & $0.212 \pm 0.058$ & $0.218 \pm 0.053$ & -1.366 & .181 \\
\hline & $\mathrm{Pz}$ & $0.220 \pm 0.067$ & $0.220 \pm 0.054$ & 0.038 & .970 \\
\hline \multirow{2}{*}{ Occipital lobe } & $\mathrm{O} 1$ & $0.216 \pm 0.057$ & $0.230 \pm 0.073$ & -2.259 & $.030^{*}$ \\
\hline & $\mathrm{O} 2$ & $0.217 \pm 0.060$ & $0.222 \pm 0.050$ & -0.786 & .437 \\
\hline
\end{tabular}

${ }^{\mathrm{z}}$ See Figure 2 for the detailed position.

* Significant at $p<.05$ level by paired t-test.

There was no statistically significant change in RLB in all the measured areas (Table 5). RMB in F4 ( $p=.021)$ and T4 ( $p=.029$ ) (Table 6), and RHB in F4 ( $p=.015)$ and O1 ( $p=.034)$ statistically significantly increased after performing the activities compared to the value before performing the activities (Table 7).

$\mathrm{RB}$ (relative power of beta) tends to increase more mainly in the parietal lobe in a state of arousal or when doing a conscious act than in a stable state (Yeon, 2013). RMB (relative power of mid beta) is known to increase when meditating, 
Table 5. Changes in Relative power of low beta (RLB) waves before and after plant cutting work

\begin{tabular}{llcccc}
\hline \multirow{2}{*}{ Brain lobe } & Site & \multicolumn{2}{c}{$\mathrm{M} \pm \mathrm{SD}(\mu \mathrm{V} 2)$} & $\mathrm{t}$ & \\
& & Before & After & & .729 \\
Prefrontal lobe & Fp1 & $0.067 \pm 0.013$ & $0.067 \pm 0.009$ & -0.349 & .885 \\
& Fp2 & $0.066 \pm 0.012$ & $0.067 \pm 0.009$ & -0.145 & .701 \\
Frontal lobe & F3 & $0.067 \pm 0.013$ & $0.067 \pm 0.012$ & 0.388 & .632 \\
& F4 & $0.068 \pm 0.013$ & $0.067 \pm 0.009$ & 0.483 & .557 \\
Temporal lobe & F7 & $0.068 \pm 0.011$ & $0.069 \pm 0.006$ & -0.592 & .851 \\
& F8 & $0.069 \pm 0.012$ & $0.069 \pm 0.010$ & -0.190 & .765 \\
Parietal lobe & Fz & $0.067 \pm 0.012$ & $0.066 \pm 0.011$ & 0.301 & .560 \\
& T3 & $0.068 \pm 0.012$ & $0.070 \pm 0.009$ & -0.589 & .623 \\
Occipital lobe & T4 & $0.068 \pm 0.011$ & $0.069 \pm 0.010$ & -0.497 & .540 \\
& T5 & $0.066 \pm 0.014$ & $0.067 \pm 0.014$ & -0.618 & .370 \\
\hline
\end{tabular}

${ }^{\mathrm{z}}$ See Figure 2 for the detailed position.

*Significant at $p<.05$ level by paired t-test.

Table 6. Changes in Relative power of mid beta (RMB) waves before and after plant cutting work

\begin{tabular}{|c|c|c|c|c|c|}
\hline \multirow{2}{*}{ Brain lobe } & \multirow{2}{*}{ Site } & \multicolumn{2}{|c|}{$\mathrm{M} \pm \mathrm{SD}(\mu \mathrm{V} 2)$} & \multirow{2}{*}{$\mathrm{t}$} & \multirow{2}{*}{$p$} \\
\hline & & Before & After & & \\
\hline \multirow{2}{*}{ Prefrontal lobe } & $\mathrm{Fp}^{\mathrm{z}}$ & $0.078 \pm 0.014$ & $0.083 \pm 0.017$ & -2.006 & .053 \\
\hline & Fp2 & $0.079 \pm 0.019$ & $0.083 \pm 0.020$ & -1.464 & .152 \\
\hline \multirow{5}{*}{ Frontal lobe } & F3 & $0.080 \pm 0.017$ & $0.081 \pm 0.016$ & -0.343 & .734 \\
\hline & $\mathrm{F} 4$ & $0.078 \pm 0.015$ & $0.082 \pm 0.015$ & -2.425 & $.021^{*}$ \\
\hline & F7 & $0.079 \pm 0.013$ & $0.082 \pm 0.015$ & -1.305 & .201 \\
\hline & F8 & $0.080 \pm 0.017$ & $0.083 \pm 0.021$ & -1.276 & .210 \\
\hline & $\mathrm{Fz}$ & $0.077 \pm 0.015$ & $0.078 \pm 0.014$ & -0.466 & .644 \\
\hline \multirow{4}{*}{ Temporal lobe } & $\mathrm{T} 3$ & $0.086 \pm 0.026$ & $0.089 \pm 0.024$ & -1.104 & .277 \\
\hline & $\mathrm{T} 4$ & $0.081 \pm 0.017$ & $0.088 \pm 0.023$ & -2.284 & $.029 *$ \\
\hline & $\mathrm{T} 5$ & $0.082 \pm 0.029$ & $0.084 \pm 0.027$ & -1.118 & .272 \\
\hline & T6 & $0.078 \pm 0.023$ & $0.080 \pm 0.018$ & -0.615 & .542 \\
\hline \multirow{3}{*}{ Parietal lobe } & P3 & $0.079 \pm 0.022$ & $0.082 \pm 0.024$ & -1.316 & .197 \\
\hline & $\mathrm{P} 4$ & $0.078 \pm 0.024$ & $0.079 \pm 0.023$ & -0.677 & .503 \\
\hline & $\mathrm{Pz}$ & $0.078 \pm 0.022$ & $0.079 \pm 0.022$ & -0.381 & .705 \\
\hline \multirow{2}{*}{ Occipital lobe } & $\mathrm{O} 1$ & $0.080 \pm 0.027$ & $0.084 \pm 0.034$ & -1.737 & .091 \\
\hline & $\mathrm{O} 2$ & $0.075 \pm 0.021$ & $0.079 \pm 0.016$ & -1.424 & .164 \\
\hline
\end{tabular}

${ }^{\mathrm{z}}$ See Figure 2 for the detailed position.

* Significant at $p<.05$ level by paired t-test.

and the higher the value, the higher the concentration level (Lee, 2011). RHB (relative power of high beta) is known to increase under severe stress or in an excited state (Jo, 2014). These three indicators are commonly related to arousal and concentration, and activities of cutting plants seem to induce concentration and a mentally awake state similar to meditation. Utilizing these results, the activities of cutting plants can be applied to those who experience psychological confusion, excessive unnecessary thinking or complicated problems, or those who use much mental energy in daily life. 
Table 7. Changes in Relative power of high beta (RHB) waves before and after plant cutting work

\begin{tabular}{llcccc}
\hline \multirow{2}{*}{ Brain lobe } & Site & \multicolumn{2}{c}{$\mathrm{M} \pm \mathrm{SD}(\mu \mathrm{V} 2)$} & $\mathrm{t}$ & \\
\hline \multirow{2}{*}{ Prefrontal lobe } & Fp1 & $0.103 \pm 0.404$ & $0.107 \pm 0.038$ & -0.540 & .593 \\
& Fp2 & $0.103 \pm 0.039$ & $0.016 \pm 0.036$ & -0.352 & .727 \\
Frontal lobe & F3 & $0.105 \pm 0.036$ & $0.109 \pm 0.038$ & -0.713 & .481 \\
& F4 & $0.100 \pm 0.034$ & $0.110 \pm 0.039$ & -2.557 & $.015^{*}$ \\
& F7 & $0.100 \pm 0.033$ & $0.106 \pm 0.038$ & -1.099 & .280 \\
Temporal lobe & F8 & $0.104 \pm 0.038$ & $0.108 \pm 0.040$ & -0.585 & .563 \\
& Fz & $0.099 \pm 0.036$ & $0.107 \pm 0.039$ & -1.785 & .083 \\
Parietal lobe & T3 & $0.107 \pm 0.037$ & $0.113 \pm 0.043$ & -1.124 & .269 \\
& T4 & $0.105 \pm 0.039$ & $0.114 \pm 0.043$ & -1.487 & .146 \\
Occipital lobe & T5 & $0.098 \pm 0.031$ & $0.107 \pm 0.042$ & -1.985 & .055 \\
& T6 & $0.094 \pm 0.023$ & $0.102 \pm 0.040$ & -1.442 & .159 \\
\hline
\end{tabular}

${ }^{\mathrm{z}}$ See Figure 2 for the detailed position.

*Significant at $p<.05$ level by paired t-test.

Table 8. Changes in Relative power of gamma (RG) waves before and after plant cutting work

\begin{tabular}{|c|c|c|c|c|c|}
\hline \multirow{2}{*}{ Brain lobe } & \multirow{2}{*}{ Site } & \multicolumn{2}{|c|}{$\mathrm{M} \pm \mathrm{SD}(\mu \mathrm{V} 2)$} & \multirow{2}{*}{$\mathrm{t}$} & \multirow{2}{*}{$p$} \\
\hline & & Before & After & & \\
\hline \multirow{2}{*}{ Prefrontal lobe } & $\mathrm{Fp} 1^{\mathrm{z}}$ & $0.178 \pm 0.134$ & $0.198 \pm 0.158$ & -0.874 & .388 \\
\hline & Fp2 & $0.176 \pm 0.128$ & $0.196 \pm 0.152$ & -0.898 & .375 \\
\hline \multirow{5}{*}{ Frontal lobe } & F3 & $0.203 \pm 0.157$ & $0.218 \pm 0.182$ & -0.614 & .544 \\
\hline & $\mathrm{F} 4$ & $0.178 \pm 0.131$ & $0.200 \pm 0.155$ & -1.194 & .241 \\
\hline & F7 & $0.161 \pm 0.116$ & $0.172 \pm 0.129$ & -0.657 & .516 \\
\hline & F8 & $0.169 \pm 0.120$ & $0.177 \pm 0.144$ & -0.411 & .683 \\
\hline & $\mathrm{Fz}$ & $0.175 \pm 0.122$ & $0.194 \pm 0.164$ & -1.054 & .299 \\
\hline \multirow{4}{*}{ Temporal lobe } & $\mathrm{T} 3$ & $0.190 \pm 0.130$ & $0.200 \pm 0.150$ & -0.492 & .626 \\
\hline & $\mathrm{T} 4$ & $0.180 \pm 0.123$ & $0.199 \pm 0.151$ & -0.880 & .385 \\
\hline & $\mathrm{T} 5$ & $0.167 \pm 0.132$ & $0.181 \pm 0.150$ & -0.845 & .404 \\
\hline & T6 & $0.153 \pm 0.113$ & $0.152 \pm 0.121$ & 0.066 & .948 \\
\hline \multirow{3}{*}{ Parietal lobe } & P3 & $0.145 \pm 0.112$ & $0.154 \pm 0.123$ & -0.507 & .616 \\
\hline & $\mathrm{P} 4$ & $0.148 \pm 0.103$ & $0.155 \pm 0.124$ & -0.435 & .666 \\
\hline & $\mathrm{Pz}$ & $0.172 \pm 0.129$ & $0.209 \pm 0.187$ & -1.342 & .188 \\
\hline \multirow{2}{*}{ Occipital lobe } & $\mathrm{O} 1$ & $0.143 \pm 0.090$ & $0.170 \pm 0.129$ & -1.562 & .128 \\
\hline & $\mathrm{O} 2$ & $0.148 \pm 0.109$ & $0.158 \pm 0.133$ & -0.663 & .512 \\
\hline
\end{tabular}

${ }^{\mathrm{z}}$ See Figure 2 for the detailed position.

"Significant at $p<.05$ level by paired t-test.

\section{Changes in RG Before and After Performing the Activities}

RG before and after performing the activities was analyzed, but there was no statistically significant difference (Table 8 ). 
Table 9. Changes in Ratio of SMR to theta (RST) waves before and after plant cutting work

\begin{tabular}{llcccc}
\hline \multirow{2}{*}{ Brain lobe } & Site & \multicolumn{2}{c}{$\mathrm{M} \pm \mathrm{SD}(\mu \mathrm{V} 2)$} & $\mathrm{t}$ & \\
& & Before & After & & .407 \\
Prefrontal lobe & Fp1 & $0.202 \pm 0.132$ & $0.221 \pm 0.122$ & -0.840 & .404 \\
& Fp2 & $0.199 \pm 0.129$ & $0.216 \pm 0.105$ & -0.845 & .106 \\
Frontal lobe & F3 & $0.208 \pm 0.085$ & $0.245 \pm 0.137$ & -1.661 & $.024^{*}$ \\
& F4 & $0.201 \pm 0.107$ & $0.233 \pm 0.124$ & -2.358 & .202 \\
Temporal lobe & F7 & $0.180 \pm 0.068$ & $0.199 \pm 0.099$ & -1.301 & .091 \\
& F8 & $0.188 \pm 0.077$ & $0.225 \pm 0.134$ & -1.742 & $.012^{*}$ \\
Parietal lobe & Fz & $0.188 \pm 0.077$ & $0.229 \pm 0.129$ & -2.653 & $.026^{*}$ \\
& T3 & $0.221 \pm 0.120$ & $0.278 \pm 0.193$ & -2.329 & .061 \\
T4 & $0.213 \pm 0.137$ & $0.266 \pm 0.181$ & -1.935 & $.026^{*}$ \\
Occipital lobe & T5 & $0.235 \pm 0.137$ & $0.291 \pm 0.202$ & -2.321 & .051 \\
\hline
\end{tabular}

${ }^{\mathrm{z}}$ See Figure 2 for the detailed position.

*Significant at $p<.05$ level by paired t-test.

\section{Changes in RST, RMT and RSMT Before and After Performing the Activities}

RST before and after performing the activities was analyzed, and RST in F4 ( $p=.024), \mathrm{Fz}$ ( $p=.012), \mathrm{T} 3$ ( $p=.026), \mathrm{T} 5$ ( $p=.026), \mathrm{O} 1$ ( $p=.019)$ and $\mathrm{O} 2$ ( $p=.017)$ statistically significantly increased after performing the activities compared to the value before performing the activities. RST in the rest areas also tended to increase, although there was no statistically significant difference (Table 9).

RMT before and after performing the activities was analyzed, and RMT in F4 ( $p=.024), \mathrm{Fz}$ ( $p=.012), \mathrm{T} 3$ ( $p=.026), \mathrm{T} 5$ $(p=.026), \mathrm{O} 1(p=.019)$ and $\mathrm{O} 2(p=.017)$ statistically significantly increased after performing the activities compared to the value before performing the activities. RMT in the rest areas tended to increase, although there was no statistically significant difference (Table 10).

RSMT before and after performing the activities was analyzed, and RSMT in F4 ( $p=.007), \mathrm{Fz}$ ( $p=.016), \mathrm{T} 4$ ( $p=.046$ ), $\mathrm{O} 1(p=.012)$ and $\mathrm{O} 2(p=.007)$ statistically significantly increased after performing the activities compared to the value before performing the activities. RSMT in the rest areas also tended to increase, although there was no statistically significant difference (Table 11).

RST (ratio of SMR to theta spectrum) occurs when attention reaches its peak (J.E. Kim, 2018), and often occurs while meditating in a nervous state (Lee, 2012). RMT (ratio of mid beta to theta) involves in attention and concentration, and the higher the RMT value, the higher the concentration level (Lee, 2011). RMT is known to increase when concentrating on one thing such as calculation and mental arithmetic or when focusing on and paying attention to a certain object (J.E. Kim, 2018). RSMT (ratio of SMR mid beta to theta) is also another objective indicator of the state of concentration (Jo, 2014; Lee, 2011; Yeon, 2013). The higher the RSMT value, the higher the concentration level (Lubar, 1991). Therefore, the significant increase in RST, RMT and RSMT can be attributed to the increased attention and concentration level after performing the activities of cutting plants, compared to the level before performing the activities. In addition, the level also significantly increased in the frontal lobe and the occipital lobe, which seems to indicate that the activities of cutting plants 
Table 10. Changes in Ratio of mid beta to theta (RMT) waves before and after plant cutting work

\begin{tabular}{|c|c|c|c|c|c|}
\hline \multirow{2}{*}{ Brain lobe } & \multirow{2}{*}{ Site } & \multicolumn{2}{|c|}{$\mathrm{M} \pm \mathrm{SD}(\mu \mathrm{V} 2)$} & \multirow{2}{*}{$\mathrm{t}$} & \multirow{2}{*}{$p$} \\
\hline & & Before & After & & \\
\hline \multirow{2}{*}{ Prefrontal lobe } & $\mathrm{Fp}^{\mathrm{z}}$ & $0.256 \pm 0.216$ & $0.303 \pm 0.239$ & -0.840 & .407 \\
\hline & Fp2 & $0.258 \pm 0.218$ & $0.296 \pm 0.220$ & -0.845 & .404 \\
\hline \multirow{5}{*}{ Frontal lobe } & F3 & $0.265 \pm 0.146$ & $0.327 \pm 0.233$ & -1.661 & .106 \\
\hline & $\mathrm{F} 4$ & $0.242 \pm 0.162$ & $0.306 \pm 0.200$ & -2.358 & $.024^{*}$ \\
\hline & F7 & $0.222 \pm 0.133$ & $0.250 \pm 0.158$ & -1.301 & .202 \\
\hline & F8 & $0.230 \pm 0.129$ & $0.300 \pm 0.245$ & -1.742 & .091 \\
\hline & $\mathrm{Fz}$ & $0.227 \pm 0.122$ & $0.293 \pm 0.213$ & -2.653 & $.012^{*}$ \\
\hline \multirow{4}{*}{ Temporal lobe } & $\mathrm{T} 3$ & $0.324 \pm 0.332$ & $0.409 \pm 0.387$ & -2.329 & $.026^{*}$ \\
\hline & $\mathrm{T} 4$ & $0.277 \pm 0.232$ & $0.383 \pm 0.331$ & -1.935 & .061 \\
\hline & $\mathrm{T} 5$ & $0.338 \pm 0.336$ & $0.402 \pm 0.323$ & -2.321 & $.026^{*}$ \\
\hline & T6 & $0.286 \pm 0.199$ & $0.376 \pm 0.334$ & -2.023 & .051 \\
\hline \multirow{3}{*}{ Parietal lobe } & $\mathrm{P} 3$ & $0.306 \pm 0.261$ & $0.351 \pm 0.273$ & -1.075 & .290 \\
\hline & $\mathrm{P} 4$ & $0.323 \pm 0.300$ & $0.362 \pm 0.272$ & -1.060 & .297 \\
\hline & $\mathrm{Pz}$ & $0.328 \pm 0.300$ & $0.367 \pm 0.235$ & -0.325 & .747 \\
\hline \multirow{2}{*}{ Occipital lobe } & $\mathrm{O} 1$ & $0.283 \pm 0.219$ & $0.461 \pm 0.513$ & -2.473 & $.019^{*}$ \\
\hline & $\mathrm{O} 2$ & $0.250 \pm 0.145$ & $0.365 \pm 0.292$ & -2.503 & $.017^{*}$ \\
\hline
\end{tabular}

${ }^{\mathrm{z}}$ See Figure 2 for the detailed position.

*Significant at $p<.05$ level by paired t-test.

Table 11. Changes in Ratio of SMR mid beta to theta (RSMT) waves before and after plant cutting work

\begin{tabular}{|c|c|c|c|c|c|}
\hline \multirow{2}{*}{ Brain lobe } & \multirow{2}{*}{ Site } & \multicolumn{2}{|c|}{$\mathrm{M} \pm \mathrm{SD}(\mu \mathrm{V} 2)$} & \multirow{2}{*}{$\mathrm{t}$} & \multirow{2}{*}{$p$} \\
\hline & & Before & After & & \\
\hline \multirow{2}{*}{ Prefrontal lobe } & $\mathrm{Fp} 1^{\mathrm{z}}$ & $0.458 \pm 0.347$ & $0.524 \pm 0.353$ & -1.379 & .177 \\
\hline & Fp2 & $0.456 \pm 0.345$ & $0.511 \pm 0.318$ & -1.290 & .206 \\
\hline \multirow{5}{*}{ Frontal lobe } & $\mathrm{F} 3$ & $0.472 \pm 0.230$ & $0.572 \pm 0.369$ & -1.727 & .093 \\
\hline & $\mathrm{F} 4$ & $0.443 \pm 0.268$ & $0.539 \pm 0.323$ & -2.874 & $.007^{*}$ \\
\hline & F7 & $0.402 \pm 0.201$ & $0.449 \pm 0.256$ & -1.044 & .304 \\
\hline & F8 & $0.419 \pm 0.206$ & $0.524 \pm 0.377$ & -1.918 & .064 \\
\hline & $\mathrm{Fz}$ & $0.414 \pm 0.197$ & $0.521 \pm 0.340$ & -2.535 & $.016^{*}$ \\
\hline \multirow{4}{*}{ Temporal lobe } & $\mathrm{T} 3$ & $0.545 \pm 0.442$ & $0.687 \pm 0.570$ & -1.801 & .081 \\
\hline & $\mathrm{T} 4$ & $0.490 \pm 0.369$ & $0.649 \pm 0.505$ & -2.066 & $.046^{*}$ \\
\hline & $\mathrm{T} 5$ & $0.573 \pm 0.460$ & $0.693 \pm 0.513$ & -1.305 & .201 \\
\hline & T6 & $0.505 \pm 0.307$ & $0.678 \pm 0.612$ & -1.895 & .067 \\
\hline \multirow{3}{*}{ Parietal lobe } & P3 & $0.551 \pm 0.441$ & $0.641 \pm 0.484$ & -0.859 & .396 \\
\hline & $\mathrm{P} 4$ & $0.595 \pm 0.510$ & $0.690 \pm 0.544$ & -0.909 & .370 \\
\hline & $\mathrm{Pz}$ & $0.609 \pm 0.504$ & $0.660 \pm 0.408$ & -0.737 & .466 \\
\hline \multirow{2}{*}{ Occipital lobe } & $\mathrm{O} 1$ & $0.496 \pm 0.318$ & $0.794 \pm 0.808$ & -2.662 & $.012^{*}$ \\
\hline & $\mathrm{O} 2$ & $0.453 \pm 0.234$ & $0.671 \pm 0.551$ & -2.857 & $.007^{*}$ \\
\hline
\end{tabular}

${ }^{\mathrm{z}}$ See Figure 2 for the detailed position.

"Significant at $p<.05$ level by paired t-test.

increased not only focused attention, but also the overall attention including unfocused attention (Lee, 2016). This is very similar to meditation, and the activities of cutting plants seem to be very effective in increasing attention to one topic. Utilizing these results, the activities of cutting plants can be applied for the purposes of strengthening attention and increasing concentration.

There is still a limitation. Since only brain wave indicators were used in analysis in this study, it is difficult to identify 
the correlation between subjective cognitive conditions and neurophysiological conditions. In addition, changes in the brain wave indicators depending on the area where brain waves occur were not considered in this study. Despite these limitations, the activities of cutting plants were found, in this study, to increase concentration through conscious activities without causing intellectual anxiety or psychological burdens, which is meaningful.

\section{Conclusion}

This study was conducted to analyze changes in brain waves before and after performing the activities of plants cutting, targeting a total of 34 adults, to identify the effects of the activities and to support the selection of target subjects. RT decreased after performing the activities of plants cutting, while RB, RMB, RHB, RST, RMT and RSMT increased. However, there was no statistically significant change in RA, RLB and RG. RT decreased in this study not because the activities were high-level tasks, but because they were the tasks that can be stably performed, and thus did not cause anxiety. This indicates that the activities of cutting plants can be applied to those who have low cognitive ability such as children, the elderly with dementia and people with intellectual disability or those who need to reduce psychological burdens through the activities. RB, RMB and RHB increased in this study, which induces concentration and a mentally awake state similar to meditation, and thus the activities of cutting plants can be applied to those who experience psychological confusion, excessive unnecessary thinking or complicated problems, or those who use much mental energy in daily life. RST, RMT and RSMT also increased, which indicates that the concentration level increased. Therefore, the activities of cutting plants can be applied for the purposes of strengthening attention and increasing concentration. In this study, the activities of plants cutting were found to increase concentration through conscious activities without causing intellectual anxiety or psychological burdens, which is meaningful.

\section{References}

Bae, J.M. 2012. Doctor Bae's sulsul health medical statistics. Seoul, Korea: Hannarae.

Gruzelier, J. 2009. A theory of alpha/theta neurofeedback, creative performance enhancement, long distance functional connectivity and psychological integration. Cogn. Process. 10(Suppl 1):101-109. DOI:10.1007/s10339-008-0248-5

Jo, H.M. 2014. Effect of essential oil of Atractylodes ovata (Thunb.) DC. Rhizome on electroencephalographic activity. Master's thesis, Kangwon National University, Chuncheon, Korea.

Kim, D.W., M.S. Kim, S.P. Kim, Y.M. Park, J.Y. Park, K.Y. Bae, S.H. Lee, J.W. Lee, C.H. Lim, Y.H. Jeon, S.H. Jin, J.H. Chae, and H.J. Hwang. 2017. Understanding and application of EEG. Seoul, Korea: Hakjisa.

Kim, J.E. 2018. Effect of linhalation of an earthy odor compound 2-Methylisoborneol on human electroencephalographic activity. Master's thesis, Kangwon National University, Chuncheon, Korea.

Kim, J.M. 2015. The Effects of horticultural therapy based on structural recall by developmental stage on institutionalized elders' cognitive, emotional, and hand functions. Master's Thesis, Catholic University of Daegu, Dagu, Korea.

Kim, T.H. 2018. Effect of inhalation of an earthy odor compound Geosmin on human electroencephalographic activity. Master's thesis, Kangwon National University, Chuncheon, Korea.

Kim, Y.J. and N.K. Chang. 2001. Changes of the prefrontal EEG (Electroencephalogram) activities according to the repetition of audio - visual learning. J. Korean Assoc. Sci. Educ. 21(3):516-528.

Korean Society of EEG Research. 2017. Art and application of EEG analysis- From basics to clinical research. Seoul, Korea: Medbook.

Kwon, Y.J., J.Y. Park, D.H. Shin, J.S. Jeon, and K.T. Park. 2006. Changes of the brain activities after learning hypothesis-generation in elementary students. J. Korean Soc. Biol. Educ. 34(1):72-80. 
Lee, M.J. 2012. The effect of men's job stress in their 40s to 50s on brain wave, heart rate variability and physiological changes -Focused on Acanthopanax senticosus extract-. Doctoral dissertation, Seokyeong University, Seoul, Korea.

Lee, S.E. 2011. Effect of volatile fragrance components of Citrus aurantiifolia and Eugenia caryophylla on electroencephalogram. Master's Thesis, Kangwon National University, Chuncheon, Korea.

Lee, S.M., Y.H. Choi, G.M. Gim, S.H. Jeong, M.S. Jeon, and S. Lee. 2017a. Effects of Horticultural Therapy Program Based on 'Relaxation-Social Support-Cognitive Behavior' Strategy on Quality of Life, Stress and Serotonin of Woman Cancer Patients - Focused on Indoor Activities -. Journal of People Plants and Environment 19(4):277-284

Lee, S.M., G.M. Gim, S.H. Jeong, S.J. Jeong, K.S. Han, Y.A. Jang, S.H. Youk, and H.J. Jang. 2017b. Change analysis of brain waves before and after the sowing work process. Proceedings of annual conference of Korean Society for Horticultural Science. 35(II):229-229.

Lee, Y.J. 2016. The Analyses of QEEG changes before and after neurofeedback alpha/theta training. Doctoral dissertation, Yeungnam University, Gyeongsan, Korea.

Lubar, J.F. 1991. Discourse on the development of EEG diagnostics and biofeedback for attention-deficit/hyperactivity disorders. Biofeedback Self Regul. 16(3):201-225.

Niedermeyer, E. and F.H. Lopes da Silva. 2005. Electroencephalography: Basic principles, clinical applications, and related fields. Philadelpia, USA: Lippincott Williams \& Wilkins.

Park, H.B. and H.M. Sung. 2006. The introduction and clinical applications of nuerofeedback. Korean J. Psychosom. Med. 14(1):8-17.

Simson, S.P. and M.C. Straus. 1998. Horticulture as therapy: Principles and practice. Binghamton, NY: The Haworth Press, Inc.

Ulrich, R.S. and R. Parsons. 1992. Influences of passive experiences with plants on individual well-being and health. In: D. Relf(Ed.), The role of horticulture in human well-being and social development: A national symposium. Portland, OR: Timber Press.

Vaitl, D., N. Birbaumer, J. Gruzelier, G. Jamieson, B. Kotchoubey, A. Kübler, D. Lehmann, W.H. Miltner, U. Ott, P. Pütz, G. Sammer, I. Strauch, U. Strehl, J. Wackermann, and T. Weiss. 2005. Psychobiology of altered states of consciousness. Psychol. Bull. 131(1):98-127.

Vernon, D., T. Egner, N. Cooper, T. Compton, C. Neilands, A. Sheri, and J. Gruzelier. 2003. The effect of training distinct neurofeedback protocols on aspects of cognitive performance. Int. J. Psychophysiol. 47(1):75-85.

Yeon, B.R. 2013. Effect of volatile organic chemicals in the essential oil of Cnidium officinale makino on electroencephalogram. Master's thesis, Kangwon National University, Chuncheon, Korea.

Yun, S.Y. 2007. Effects of the application of horticultural therapy based on Pincus' theory of rehabilitation practice on demented elders' daily activity functions and physiological changes. Doctoral dissertation, Catholic University of Daegu, Daegu, Korea. 